\title{
Review \\ Methods for design flood estimation in South Africa
}

\author{
JC Smithers* \\ School of Engineering, University of KwaZulu-Natal, South Africa
}

\begin{abstract}
The estimation of design floods is necessary for the design of hydraulic structures and to quantify the risk of failure of the structures. Most of the methods used for design flood estimation in South Africa were developed in the late 1960s and early 1970 s and are in need of updating with more than 40 years of additional data currently available and with new approaches used internationally. This paper reviews methods used for design flood estimation in South Africa and internationally and highlights research needs in order to update the methods used for design flood estimation in South Africa.
\end{abstract}

Keywords: Design flood estimation, South Africa, research needs

\section{Introduction}

Recent floods in South Africa, such as those of February 2000 which occurred in the north-eastern part of South Africa, Zimbabwe and Mozambique, flooding in the Western Cape in 2005 and floods in the Free State and Eastern Cape in 2011, highlight the need to re-assess the risks associated with floods Realistic design flood estimation, where the magnitude of a flood is associated with a level of risk (e.g. return period), is necessary in the planning, design and operation of hydraulic structures (e.g. bridges, culverts, dam spillways, drainage canals etc) for the preservation of human life and property (Rahman et al., 1998; Pegram and Parak, 2004; Reis and Stedinger, 2005).

Flood frequency analysis remains a subject of great importance owing to its economic and environmental impact (Pilgrim and Cordery, 1993; Bobee and Rasmussen, 1995). However, reliable estimates of flood frequency in terms of peak flows and volumes remain a challenge in hydrology (Cameron et al., 1999). Cordery and Pilgrim (2000) express the opinion that the demands for improved estimates of floods have not been met with any increased understanding of the fundamental hydrological processes. The urgency for new approaches to design flood estimation in South Africa are highlighted by Alexander (2002), Smithers and Schulze (2003) and Görgens (2007). Acording to Van der Spuy and Rademeyer (2010), there is still no universally applicable method for design flood estimation in South Africa.

Standard techniques for design flood estimation have been developed for most countries. These generally include statistical analyses of observed peak discharges and event modelling using rainfall-runoff techniques. Observed streamflow data are often not available at the site of interest and rainfall eventbased methods have to be used. Reviews of approaches to design flood estimation are contained in Cordery and Pilgrim (2000) and Smithers and Schulze (2001).

\footnotetext{
To whom all correspondence should be addressed.

sim +2733 2605490; fax: +273326 5818; e-mail: smithers@ukzn.ac.za

Received 16 February 2011; accepted in revised form 25 June 2012.
}

The majority of design decisions in Australia are made for small- $\left(<25 \mathrm{~km}^{2}\right)$ and medium-sized $\left(<250-1000 \mathrm{~km}^{2}\right)$ catchments, where no observed flood data are available (Pilgrim, 1987) This view is similar to that expressed in HRU (1972), in which it was stated that the most frequent need for estimating design floods was for catchments $<15 \mathrm{~km}^{2}$, followed less frequently by intermediate-sized catchment with areas ranging from 10 to $5000 \mathrm{~km}^{2}$. Pilgrim and Cordery (1993) estimate that the expenditure in Australia on hydraulic structures in small, rural catchments is the greatest (46\%), followed by that in urban drainage (26\%) and in large catchments (28\%). However, most techniques for design flood estimation are focussed on large catchments. Although the estimation of design floods for small catchments is required more frequently than estimates for large catchments, an attempt is made in this paper to review procedures for design flood estimation at both small and larger catchments scales.

The objective of this paper may be summarised as follows:

- To present a brief overview of methodologies currently used to estimate design floods in South Africa, including methods used internationally.

- To present perceived deficiencies in the techniques currently used to estimate design floods in South Africa.

- To identify and discuss research needed to improve the estimation of design floods in South Africa.

The following section contains a broad overview of techniques which may be used for design flood estimation. This is followed by a description of approaches that may be adopted in situations where long records of gauged streamflow data are available and alternatively in situations where no, or inadequate, data are available. More emphasis is placed on the review of techniques to estimate design floods at ungauged sites, or sites at which the streamflow data are inadequate, as this is the situation generally faced by design engineers and hydrologists.

\section{Approaches to design flood estimation}

Procedures for design flood estimation may be broadly categorised as methods based on the analysis of observed floods and rainfall-based methods (Smithers and Schulze, 2003). According to HRU (1972), design floods may be estimated 


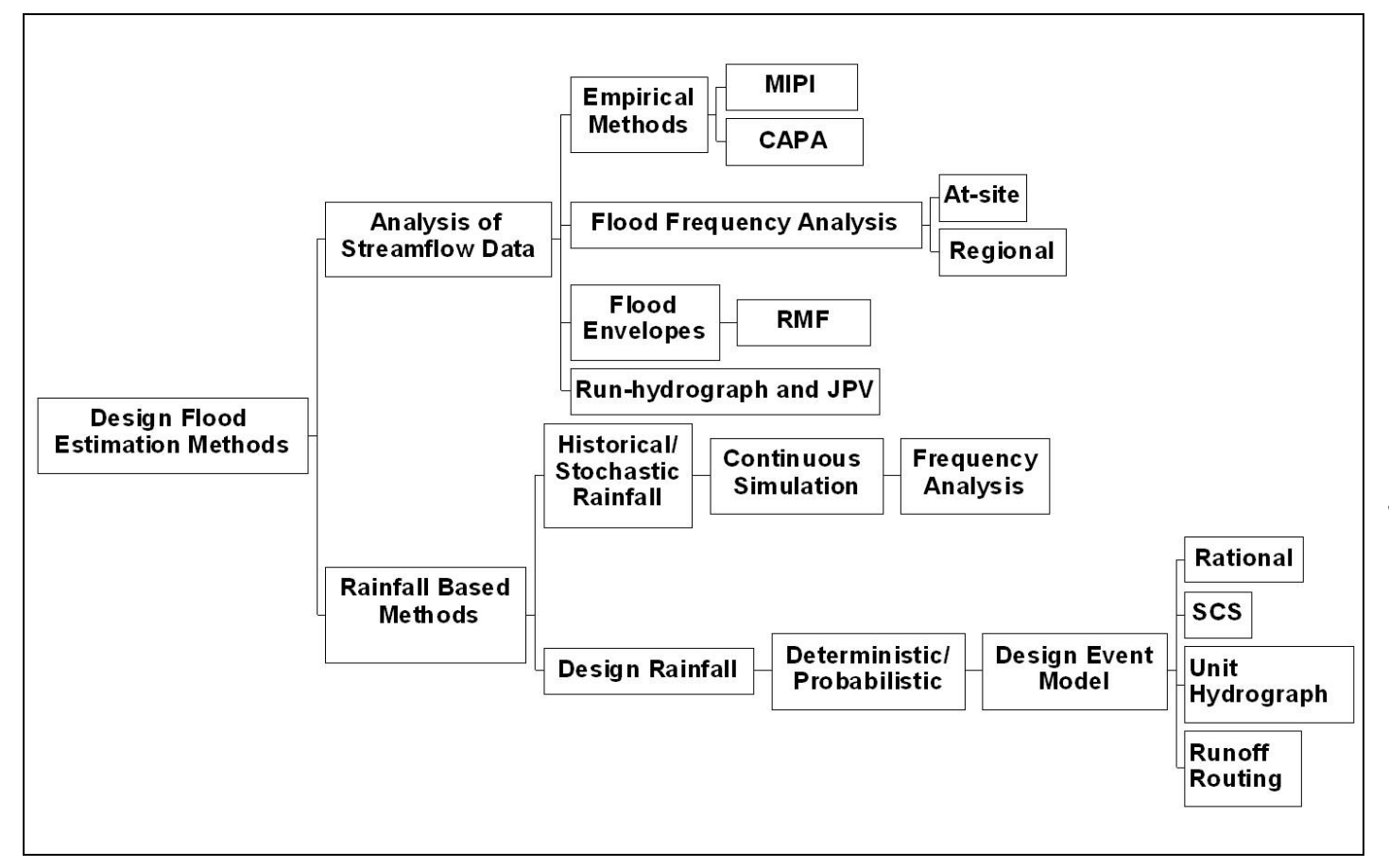

Figure 1 Approaches to design flood estimation in South Africa (after Smithers and Schulze, 2001) using either a statistical approach, which is an ordering and transposition of past experience, or a deterministic approach, in which rainfall is translated into a flood. Methods used for design flood estimation in South Africa are based on empirical, deterministic and probabilistic approaches (Pegram and Parak, 2004; Van der Spuy and Rademeyer, 2010). Pegram (1994) presents a decision tree for the selection of design flood estimation method in South Africa. Alexander $(1990 ; 2001)$ classifies the methods for design flood estimation in South Africa as direct statistical analysis, regional statistical analysis, deterministic and empirical methods. SANRAL (1986) identifies empirical, statistical, as well as the Rational, SCS, run-hydrograph and synthetic unit hydrograph approaches as appropriate and promising methods for estimating design floods in South Africa. The methods used for design flood estimation in South Africa are categorised and summarised in Figure 1.

Some similar and alternate approaches to design flood estimation are used internationally. Beven (2000) distinguishes between statistical estimation based on samples of observed floods at a site, regionalisation methods for catchments with no data, and methods based on rainfall-runoff modelling. The ASCE (1997) summarises the use of simplified methods such as formulae, regression equations and envelope curves, and also includes rainfall-runoff analysis for a period of record where a historical sequence of rainfall is input to the model to generate the variable of interest, which can then be subjected to frequency analyses, i.e., continuous simulation modelling. The Flood Estimation Handbook (FEH) for the UK provides two main approaches to flood frequency estimation (Reed, 1999). The first is an index flood approach which utilises growth curves and is the first choice when there is a long record of gauged flow at or close to the site of interest, and which may be used for catchments with areas larger than $0.5 \mathrm{~km}^{2}$. The second approach is the Flood Studies Report (FSR) rainfall-runoff method which may be used for catchments with areas up to $1000 \mathrm{~km}^{2}$. In Australia methods for design flood estimation include empirical formulae, at-site or regional frequency relationships and rainfall-based methods (Australian Institution of Engineers, 1977).
Campbell et al. (1986) listed the problems facing hydrologists and engineers in South Africa when estimating floods in small catchments $\left(<100 \mathrm{~km}^{2}\right)$ as the lack of hydrological data and the absence of suitable guidelines on the selection and accuracies of methods for estimating design floods. A survey undertaken by Campbell et al. (1986) indicated the following:

- The Rational Method was the most commonly used method and the use of the Time Area, SCS and Kinematic procedures was significant.

- A significant need for the estimation of the storm hydrograph in addition to the peak discharge was identified.

- Most applications were in catchments with area less than $10 \mathrm{~km}^{2}$.

- A lack of familiarity with the various techniques and the availability of adequate observed streamflow data were highlighted by the survey.

Most of the methods used for design flood estimation in South Africa were developed in the late 1960s and early 1970s, as summarised in HRU (1972), and are in need of updating, with more than 40 years of additional data currently available (Van der Spuy and Rademeyer, 2010) and with new approaches used internationally (Smithers and Schulze, 2003). Software to implement design flood procedures currently used in South Africa has been developed (e.g. Schulze et al., 1992; van Dijk, 2005; Gericke, 2010).

\section{Methods based on the analysis of floods}

At sites where observed streamflow data are available, a choice between some form of flood frequency analysis and a method based on rainfall has to be made. A direct estimate of the flood for a given exceedance probability is obtained via frequency analysis, but rainfall records are generally longer, more abundant and less variable over time than streamflow records (Pilgrim and Cordery, 1993).

In general, methods based on the analyses of floods are probabilistic by nature and hence are suitable for estimating 
design floods. Cordery and Pilgrim (2000) summarise the methods based on the analysis of observed floods as empirical formulae, flood frequency methods and envelope curves.

\section{Empirical formulae}

Empirical formulae are algorithms which generally relate peak discharge to catchment size and other physiographical and climatic catchment characteristics. Their use is extremely hazardous, particularly if they are not calibrated from the catchment in question and should be avoided (Cordery and Pilgrim, 2000). A similar sentiment is expressed by the NTC (1981), which states that empirical and experienced-based methods should only be used for checking other methods.

Roberts (1963; 1965), cited by Alexander (1990), developed a method to estimate design peak discharges in South Africa as a function of catchment area, a catchment coefficient and a coefficient derived from the Hazen distribution. Pitman and Midgley (1967) identified 7 homogeneous flood-producing regions in South Africa and developed a co-axial diagram with 4 variables (return period, locality, catchment area and peak discharge) to estimate design floods in South Africa. The method, termed the MIPI method, frequently estimates acceptable flood peaks (Van der Spuy and Rademeyer, 2010). Herbst (1968), cited by Alexander (1990), further developed the relationship and also included mean annual precipitation (MAP) and coefficient of variation of the floods as variables.

The Catchment Parameter method (CAPA), developed by McPherson (1984), is an index-flood type approach with the mean annual flood (index) estimated as a function of catchment area, slope, MAP and a catchment shape parameter. The scaling factor used is a function of MAP and exceedance probability of the design (Van der Spuy and Rademeyer, 2010).

\section{Flood frequency analysis}

Design flood estimation may be performed by a frequency analysis of observed flows where these are available and adequate in both length and quality. The analysis may be performed at a single site, or, preferably, a regional approach should be adopted. Using observed data in flood frequency estimation assumes that the data are stationary. This is often not the case due to land cover and land use changes within the catchment and also as a consequence of climate change. Both at-site and regional approaches are reviewed in the following sections.

\section{At-site analysis}

The procedures for direct frequency analysis of observed peak discharge involves selecting and fitting an appropriate theoretical probability distribution to the data. These procedures are referenced in standard hydrology texts (e.g. Chow et al., 1988; Stedinger et al., 1993). As shown by Schulze (1989) and Smithers and Schulze (2000), the question of selecting an appropriate distribution has received considerable attention in the literature, with diverging opinions expressed by various authors. Schulze (1989) questions whether a suitable probability distribution can be selected, given that the best distribution varies with, inter alia, the season, storm type and duration and regional differences. Schulze (1989) highlights the problem of short data sets and extrapolation beyond the record length. He also illustrates typical measurement errors as well as inconsistency, nonhomogeneity and non-stationarity of data, all of which violate the assumptions made when fitting a distribution to the data.
Beven (2000) identifies the following limitations of a direct statistical approach:

- The correct distribution of the flood peaks is unknown and different probability distributions may give acceptable fits to the available data, but result in significantly different estimates of design floods when extrapolated.

- The records of gauged runoff are generally short and the calibration of the gauging structures may not be very robust. Hence the sample only represents a small distribution of the floods at the site and the fitted distribution may be further biased by gauging errors.

- The frequency of flood-producing rainfalls and land-use characteristics may have changed during the period of historical measurement.

- The fitted distribution does not explicitly take into account any changes in the runoff generation processes for higher magnitude events.

Where long records of streamflow are available at a site, a frequency analysis of observed data may be performed. However, many studies have shown that a regional approach to frequency analysis results in more reliable design estimates.

\section{Regional analysis}

Given that the data at a site of interest will seldom be sufficient, or available, for frequency analysis, it is necessary to use data from similar and nearby locations (Stedinger et al., 1993). This approach is known as regional frequency analysis and utilises data from several sites to estimate the frequency distribution of observed data at each site (Hosking and Wallis, 1987; 1997). Regional frequency analysis assumes that the standardised variate has the same distribution at every site in the selected region and that data from a region can thus be combined to produce a single regional flood, or rainfall, frequency curve that is applicable anywhere in the region with appropriate site-specific scaling (Cunnane, 1989; Gabriele and Arnell, 1991; Hosking and Wallis, 1997). Regionalisation enables a frequency analysis of short records of annual floods to be performed by assisting with the identification of the shape of the parent distribution and leaving the measure of scale to be estimated from the atsite data (Bobee and Rasmussen, 1995). In the context of flood frequency analysis, regionalisation refers to the identification of homogeneous flood response regions and the selection of an appropriate frequency distribution for the selected regions (Kachroo et al., 2000). Within a homogeneous region, historical data can be pooled to obtain efficient estimates of the parameters of the distribution and hence robust quantile estimates (Kachroo et al., 2000) with smaller standard errors (Mkhandi et al., 2000). Thus, the concept of regional analysis is to supplement the time-limited sampling record by the incorporation of spatial randomness using data from different sites in a region (Schaefer, 1990; Nandakumar et al., 1995).

Regional approaches can also be used to estimate events where no information exists (ungauged) at a site (Pilon and Adamowski, 1992). However, care must be exercised to ensure that such an approach is not applied outside of the region where the method was developed, nor outside of the range of observations used to develop the method (Cordery and Pilgrim, 2000).

In nearly all practical situations a regional method will be more efficient than the application of an at-site analysis (Potter, 1987). This view is also shared by Lettenmaier (1985; cited by Cunnane, 1989) who expressed the opinion that 'regionalisation is the most viable way of improving flood quantile estimation'. 
Similarly, Hosking and Wallis (1997 p. 3), after a review of literature up to 1996, advocate the use of regional frequency analysis based on the belief that a "well conducted regional frequency analysis will yield quantile estimates accurate enough to be useful in many realistic applications'. This opinion was also expressed by Cordery and Pilgrim (2000 p. 196), who conclude that regional approaches are 'the only sure basis for improved flood prediction'. According to Alexander (1990), regional statistical analyses provide a basis for improving the estimates of the parameters of the distribution at both gauged sites with short records and at ungauged sites. The advantages of regionalisation are thus accepted by numerous respected researchers.

The index flood-based procedure developed by Hosking and Wallis (1993; 1997), and which utilises L-moments, appears to be a robust procedure and has been applied in a number of studies. For example, the methodology has been successfully applied by Smithers and Schulze (2000; 2000) to estimate both short- and long-duration design rainfalls in South Africa. A cluster analysis of site characteristics is used to identify potential homogeneous regions, which allows for independent testing of the at-site data for homogeneity. Methods based on L-moments are used for frequency estimation, screening for discordant data and testing clusters for homogeneity (Hosking and Wallis, 1993; 1997).

Much research in recent years has focussed on the identification of homogeneous regions, as geographical proximity does not imply hydrological similarity (Bobee and Rasmussen, 1995). Kachroo et al. (2000) reviewed recent literature and concluded that no objective methods of regionalisation are universally accepted. A significant development in the identification of homogeneous regions is the region of influence approach developed by Burn $(1990 ; 1990)$ and Zrinji and Burn (1994) and which has been adopted by the FEH (Reed, 1999).

According to Alexander (1990), no comprehensive studies of regional statistical analysis methods have been made in South Africa since the early 1970s. He outlines a generalised procedure for regional statistical analyses which consists of plotting scaled growth curves and rejecting stations which have growth curves inconsistent with the remaining stations. According to Alexander (1990), the distribution of gauging stations in South Africa is too sparse to pre-determine hydrologically homogeneous regions and suggests that overseas concepts of identifying homogeneous regions are not valid in South Africa (Alexander, 1990; 2001). As pointed out by Smithers and Schulze (2003), using Alexander's regional approach will result in duplication of effort by users and inconsistent results.

A tentative regionalisation based on the regions identified by Kovacs (1988) was performed by Van Bladeren (1993) for the KwaZulu-Natal and former Transkei regions. He noted that further regionalisation was necessary and that a strong relationship existed between the mean annual flood and catchment area. Mkhandi et al. (2000) used the L-moment based procedures developed by Hosking and Wallis (1993) to identify 13 homogeneous flood-producing regions in Southern Africa. A initial regionalisation of the annual maximum series of peak discharges for KwaZulu-Natal in South Africa has been derived by Kjeldsen et al. (2002). The index flood method, as proposed by Hosking and Wallis $(1993 ; 1997)$, was utilised in the study and 2 homogeneous regions were identified. In order to rescale the regional growth curve at an ungauged site, Kjeldsen et al. (2001) developed relationships to estimate the index flood as a function of the MAP and catchment area.

Nortje (2010) developed a Regional Estimation of Extreme Flood Peaks by Selective Statistical Analyses (REFSSA) method to estimate extreme flood peaks from regional flood peak data in South Africa and showed that the method was applicable to estimate the 1000 and 10000 return period events for catchment areas ranging from $100-7000 \mathrm{~km}^{2}$ within 2 large drainage regions in South Africa, but cautioned against using the results outside of these regions. Similar recorded maximum peak floods are used to define 'similar hydrological regions' and the REFSSA method is suited to regions which have one or two extreme outliers in the peak discharge record, as is typical in many catchments in South Africa (Nortje, 2010). The REFSSA method uses the annual maximum flood peaks from a catchment and record maximum flood peaks from 'similar hydrological regions' which are transformed to the site under investigation in proportion to the ratio of the square root of their respective catchment areas. Nortje (2010) acknowledges that subjectivity in delineating 'similar hydrological regions' will result in different results when using the REFSSA method and recommends further development and assessment of the method.

The advantages of a regional approach to frequency analysis for design flood estimation are evident from many studies reviewed. This has led to the adoption of a regional approach as the recommended approach for design flood estimation by some countries (e.g. Australia and UK).

\section{Probability distribution fitting}

Both at-site and regional flood frequency analysis require the fitting of a probability distribution to the data. Smithers and Schulze (2000) summarise approaches available for estimating the parameters of a selected distribution as the Method of Moments (MM), Maximum Likelihood Procedure (MLP), Probability Weighted Moments (PWM), L-Moments (LM), Bayesian Inference and non-parametric methods. The use of L-moments to fit distributions has received extensive coverage in the literature (Guttman, 1992; Pilon and Adamowski, 1992; Guttman, 1993; Guttman et al., 1993; Lin and Vogel, 1993; Vogel and Fennessy, 1993; Vogel et al., 1993; Vogel et al., 1993; Wallis, 1993; Gingras and Adamowski, 1994; Zrinji and Burn, 1994; Hosking, 1995; Hosking and Wallis, 1995; Karim and Chowdhury, 1995; Hosking and Wallis, 1997). L-moments are reported to have less bias when compared to other techniques. Bobee and Rasmussen (1995) describe the use of L-moments for distribution fitting as an 'eye-catching' development for flood frequency analysis while Cordery and Pilgrim (2000) 'welcome' the developments of L-moments. However, Bobee and Rasmussen (1995) caution that L-moments may be too robust and outliers may be given too little significance, while Cordery and Pilgrim (2000) emphasise that the use of L-moments does not entirely overcome the fundamental problem of selecting an appropriate distribution for a sample from a population with an unknown distribution.

The recommended distribution for flood frequency analyses in the USA is the log-Pearson Type 3 (LP3), fitted using the at-site mean and standard deviation and a regionalised estimate of the coefficient of skewness (Stedinger et al., 1993). Details are contained in USWRC (1976) and updated in the subsequent Bulletin 17B publication (IACWD, 1982) which includes procedures for dealing with outliers and conditional probability adjustment. Potter and Lettenmaier (1990) showed that an index flood approach using a GEV distribution performed better than the procedures contained in Bulletin 17B.

For direct statistical analysis Alexander $(1990 ; 2001)$ recommends either the Method of Moments or Probability 
Weighted Moments for fitting distributions. The literature indicates that L-moments are widely used and have been adopted as a standard approach in, for example, the UK. Although some caution and criticism of the use of L-moments is also evident in the literature, further investigation of L-moments for possible general use in South Africa is warranted. Alexander (1990; 2001) recommends the use of the LP3 probability distribution for design flood estimation in South Africa while Görgens (2007) used both the LP3 and GEV distributions and both distributions are applicable in South Africa (Van der Spuy and Rademeyer, 2010). Mkhandi et al. (2000) found that the Pearson Type 3 distribution fitted by PWM to be the most appropriate distribution to use in 12 of the 15 relatively homogenous regions identified in Southern Africa.

\section{Flood envelopes and RMF}

In the maximum envelope approach, the largest observed discharges are usually plotted against catchment area, both on logarithmic axes. An envelope is sketched to include all the data points. Approximate estimates are possible, provided that data from catchments similar to the one of interest were included in the analysis (Cordery and Pilgrim, 2000). Maximum peak discharges can be determined at ungauged sites using envelope curves (ASCE, 1997). The envelope tends to increase as the record length increases and as larger floods are observed.

The HRU (1972) provided a set of regionalised maximum observed flood peak envelopes for South Africa. Kovacs (1988) developed comprehensive Regional Maximum Flood (RMF) envelopes for South Africa. This approach has been stated to be reliable in medium-sized catchments (Alexander, 1990). Görgens et al. (2007) found that recent flood peaks in some regions in South Africa have exceeded the envelopes set by Kovacs (1988) and therefore need to be updated. A significant shortcoming of the RMF method is that no exceedance probability is associated with the RMF (Nortje, 2010).

\section{Run-hydrograph and joint peak-volume methodology}

The run-hydrograph technique, as detailed in Hiemstra et al. (1976), Hiemstra and Francis (1979) and Hiemstra (1981), is based on a regional analysis of historical data but was recommended, soon after its development, to only be used to check the results from other methods (SANRAL, 1986). Although no further evaluation of the method has been documented since the report by SANRAL (1986), Alexander (1990) does not recommend the run-hydrograph procedure for general use in South Africa, while Alexander (2001) concedes that the run-hydrograph method has advantages compared to the unit hydrograph method and concludes that the run-hydrograph method requires further development. The run-hydrograph method is endorsed for use in South Africa by Pegram (1994).

Görgens (2007) further developed the run-hydrograph concept for South Africa which considers the joint probability of hydrograph volumes and peaks and is termed by Görgens (2007) as the Joint Peak-Volume (JPV) design flood methodology. The methodology enables the estimation of the exceedance frequency of a design flood volume given a design peak discharge using a regionally-pooled methodology. In addition, a regionalised index-flood type approach was developed to estimate the design peak discharges with catchment area, catchment slope, mean annual runoff and region (either as a pooled
K-region, with K-regions as delineated by Kovacs (1988), or veld zone group, with veld zones as delineated by HRU (1972)) used as predictor variables to estimate the mean of the annual maximum flood peaks. For application at ungauged sites, a pooled estimate of the coefficient of variation and estimated mean of the flood peaks is used to estimate the standard deviation of the flood peaks while a pooled estimate of the coefficient of skewness is used. In practice, the user may also apply a 'narrow pool' approach to estimate the standard deviation and coefficient of skewness at an ungauged site by using the characteristics of selected catchments. The estimated index flood at an ungauged site may be adjusted using the ratio of the estimated and actual mean of the flood peaks at a nearby similar catchment which has observed flood peaks.

Similarly, Görgens (2007) derived regional relationships between the log of the standardised peaks and standardised volumes for 3 pooled K-regions and 3 pooled veld zone types for Peak Over Threshold (POT) series in South Africa. Predictor variables used in the regional regressions were catchment area, catchment lag time, mean annual runoff and pooling region. The standard deviation of the POT flood volumes can be estimated using the coefficient of variation of the pooled data sets and the mean estimated using the pooled multivariate regressions. Similar approaches (multivariate regressions, use of pooled $\mathrm{CV}$ and estimated mean to estimate standard deviation, and plots of CV of POT peak isozones) were developed to estimate the mean of the POT series with catchment area, catchment slope, mean annual runoff and region used in the regressions. Görgens (2007 p. 21) recommends that both the K-regions and veld-zone fixed geographic pooling groups should be used to estimate the pairs of the mean and standard deviation of the POT series, as 'each of the pairs is equally likely'.

Görgens (2007) also developed typical regionalised and standardised hydrographs for South Africa. These were developed for the K-regions (as delineated by Kovacs, 1988) and veld zone pools with additional classifications of smaller $\left(<1000 \mathrm{~km}^{2}\right)$ or larger catchments $\left(>1000 \mathrm{~km}^{2}\right)$ and for 5 ranges of standardised peak values. The selection of hydrographs to use should be guided by the shape variation, the conservativeness of the resulting flood volumes and the users' sense of uncertainty in the data used. Given the large variations in the standardised hydrographs presented for the various categories within the pooled regions, these considerations are very subjective and will require experienced practitioners to be utilised effectively.

Görgens (2007) assessed the JPV methodology by comparing results of the method to at-site estimates and against results produced by the synthetic unit hydrograph (HRU, 1972). Data from sites used in the analysis to derive the synthetic unit hydrograph as applied in South Africa were used in the assessment and it is not clear if these are independent of the sites used in the development of the JPV methodology. The results show that the wide-pool GEV results were generally better than either the unit hydrograph or the wide-pooled LP3 results, but resulted in considerable over-estimation in 3 catchments, where Görgens (2007) demonstrated that simple adjustments from a donor catchment could ameliorate the over-estimation.

\section{Rainfall-based methods}

The situation which faces design engineers and hydrologists most frequently is when no, or inadequate, streamflow data are available at the site of interest. As indicated in Fig. 1, the 
choices available in such a situation are between event (Unit Hydrograph, Rational Method, SCS) and continuous simulation rainfall-based methods. The advantages of rainfall-runoff models for design flood estimation may be summarised as follows (Schulze, 1989; Rahman et al., 1998):

- Generally longer rainfall records at more sites, and with better quality, are available for analysis compared to streamflow records.

- Measurement errors, inconsistencies in the data and nonhomogeneous streamflows make the data unsatisfactory for direct frequency analysis.

- Similarly, non-stationary streamflow records as a result of changing catchment conditions can render the streamflow record unsatisfactory for direct frequency analysis.

- Areal extrapolation of rainfall records can be achieved more easily than runoff records.

- Physical features of a catchment can be incorporated into a rainfall-runoff model.

- The historical, current or expected future conditions of land use within a catchment can be modelled.

\section{Design event models}

The widespread use of design event models (e.g. Rational, Unit Hydrograph and SCS) is related to their lumping of complex, heterogeneous catchment processes into a single process, their ability to handle individual events, and simple model application (Houghton-Carr, 1999). The event-based approach greatly simplifies the estimation of catchment conditions prior to the occurrence of an extreme event, even when rainfall-runoff modelling is performed to estimate the flood hydrograph (Cameron et al., 1999). One of the major limitations of design event-based models is the assumption that, for representative inputs and model parameters, the frequency of the estimated flood is equal to the frequency of the input rainfall (Pilgrim and Cordery, 1993; Rahman et al., 2002). This assumption is likely to introduce significant bias in the frequency of flood estimates and the validity of this assumption is crucial to the accuracy of this approach (Rahman et al., 1998). Considerable uncertainty is present in inputs such as storm duration, the spatial and temporal distribution of the design storm and model parameters (Rahman et al., 1998). Design event-based approaches consider the probabilistic nature of rainfall, but ignore the probabilistic behaviour of other inputs and parameters (Rahman et al., 2002). Event-based methods recommended for use in South Africa are generally applied in a deterministic manner and hence suffer from the limitations of this approach. Four general approaches are suggested by Pilgrim and Cordery (1993) to maintain the required probability for the selected flood, with Options (ii) to (iv) listed below adopted in Australia (Pilgrim, 1987; Pilgrim and Cordery, 1993):

(i) Frequency analysis of synthetic streamflow generated by a continuous rainfall-runoff from long records of rainfall

(ii) Joint probability analysis of variables contributing to the flood discharge

(iii) Use of median values for model parameters

(iv) Values derived by comparison of floods and rain of the same probability.

The Rational, SCS, Gradex, Unit Hydrograph and runoff-routing are listed by Cordery and Pilgrim (2000) as commonly used design event methods for flood estimation. Event models used in South Africa are briefly discussed in the following sections.

\section{Unit hydrographs}

The unit hydrograph approach to design flood estimation is detailed in most hydrology texts (e.g. Chow et al., 1988; Maidment, 1993). The method assumes a characteristic linear response from a catchment and hence may not be accurate for estimating large floods. However, careful use can provide good flood estimates. A limitation of a unit hydrograph approach is the assumption of spatial uniformity of rainfall (Chow et al., 1988; Maidment, 1993). An advantage of the method is the estimation of the entire hydrograph, which is important where storage within a catchment has a significant impact on floods.

For catchment areas ranging from 15 to $5000 \mathrm{~km}^{2}$, the HRU (1972) describes a unit hydrograph technique for application in South Africa. Data from only 92 steamflow gauges with catchment areas ranging from 21 to $22163 \mathrm{~km}^{2}$, were used in the analysis. Nine veld zone types were identified in South Africa and dimensionless unit hydrographs were derived for each zone. The number of catchments represented in each zone ranged from 5 to 18 . A co-axial diagram to estimate mean storm losses in the 9 veld zones was developed. Görgens et al. (2007) found that the storm loss curves are still representative of average design storm losses in Veld Zone 1, 2, 3, 8 and 9, but may be underestimating runoff percentages in Veld Zones 4, 5, 6 and 7, and expressed concern about the lack of variability over the range of return periods. SANRAL (1986) recommend that the unit hydrograph approach is a reliable method for catchments ranging in size from 15 to $5000 \mathrm{~km}^{2}$. Bauer and Midgley (1974) developed the simple-to-apply lag-route method of design flood estimation in South Africa, based on the results of the unit hydrograph technique.

No development or refinement of the unit hydrograph methods for South Africa have been published since they were developed by the HRU (1972) in the late 1960s and early 1970s. As detailed by Smithers and Schulze (2003), regional techniques for frequency analysis have become the standard and preferred approach in some countries. In addition, longer rainfall and streamflow records are currently available for analysis, computing power has expanded enormously and detailed databases of climatic and catchment physiographic characteristics are available at a national scale. While the regionalisation of South Africa into 9 veld zone types, based on data from only 92 flow gauging stations, was pioneering work in the 1960s, a refined regionalisation of homogeneous hydrological response regions in the country is now possible.

Unit hydrograph approaches are widely used internationally for design flood estimation. For example, in the UK a unit hydrograph and loss model is included in the Flood Estimation Handbook (FEH) and is widely used for 3 reasons (HoughtonCarr, 1999):

- The model is relatively well understood.

- The model can be easily and generally derived for any site.

- The simple structure of the model allows the incorporation of local data.

\section{Rational Method}

The Rational Method is widely used throughout the world for both small rural and urban catchments (Pilgrim and Cordery, 1993; Alexander, 2001) and is the most widely used method of estimating design flood peak discharges using design rainfall as input as it is easy to understand and simple to use (Parak and Pegram, 2006). The Rational Method is viewed as an approximate simplified technique for design flood estimation in the 
USA which requires little effort to apply (ASCE, 1997). The method is an approximate deterministic method and a major weakness is the judgement required to determine the appropriate runoff coefficient and the variability of the coefficients between different hydrological regimes (Pilgrim and Cordery, 1993). The Rational Method computes only flood peaks and is sensitive to the input design rainfall intensity and the selection of the runoff coefficient which is based on the experience of the user. The method assumes that the peak discharge occurs when the duration of the rainfall event is equal to the time of concentration of the catchment and that the rainfall intensity does not vary and is distributed uniformly over the catchment. As a consequence of these assumptions, the Rational Method is recommended to be applied on catchments with areas $<15$ $\mathrm{km}^{2}$ in South Africa (HRU, 1972). However, Pegram (2003) showed that the Rational Method can be applied to much larger catchment sizes than conventionally accepted.

The HRU (1972) outlines a deterministic Rational Method approach to design flood estimation in South Africa which is suitable for application in catchments with areas of up to 15 $\mathrm{km}^{2}$ and the Rational Method is recommended for use in South Africa (Alexander, 1990; 2001; SANRAL, 2007; Van der Spuy and Rademeyer, 2010). The runoff coefficient may be estimated as a function of MAP, catchment land cover, permeability and steepness, vegetation cover and return period. The return period adjustment factor decreases the runoff coefficient for events with return periods $<50$ years. The return period adjustment factor as presented by SANRAL (1986) and Alexander (2001) are different. Alexander (1990) advocates the calibration of the Rational Method with local data, where it is available.

Although a return period adjustment factor for the application of the Rational Method in South Africa is advocated (SANRAL, 2007; Van der Spuy and Rademeyer, 2010), the method is still applied in a deterministic manner and the adjustment factor does not constitute a probabilistic approach. When used circumspectly, the Rational Method can give good results compared to other methods (SANRAL, 2007).

The experience of the user and the selection of appropriate runoff coefficients are essential for the successful application of the Rational Method. In addition, Cordery and Pilgrim (2000) identify the practical difficulties of estimating the catchment response time because regional differences in the time of concentration cannot be easily explained by measured catchment characteristics. Both Pilgrim and Cordery (1993) and Cordery and Pilgrim (2000) recommend a probabilistic approach to determine the runoff coefficient for the Rational Method. According to Parak and Pegram (2006), a probabilistic approach to the application of the Rational Method is required in order to convert a design rainfall directly into a design peak discharge. This will overcome many of the limitations associated with the deterministic application of the Rational Method.

The advantage of empirical methods is that they avoid the assumptions which are necessary to convert a design rainfall to a design flood (Pegram and Parak, 2004). Thus a regionalised probabilistic approach to the Rational Method, as used for example in Australia (Australian Institution of Engineers, 1977; Pilgrim, 1987), enables the direct conversion of a design rainfall event into a design flood event with the same return period.

\section{Probabilistic Rational Method and SDF}

Alexander (2002a; 2002b; 2002d) developed a 'Standard Design Flood' (SDF) method, which is in effect a calibrated Rational Method or probabilistic-based approach to the application of the Rational Method. Rain gauges were assigned to 29 representative catchments in South Africa which have observed flow data and the Rational runoff coefficient (' $\mathrm{C}$ ' factor) was calibrated until the design flood estimated using design rainfall values equalled the value computed directly from the gauged flow data. Some subjective adjustment was performed to the calibrated runoff coefficients to 'produce a more conservative estimate' (Alexander, 2002b p. 9). The 29 catchments were grouped into 8 larger regions and verifications were performed at 84 sites where, on average, the standard design flood exceeded the at-site values by $60 \%$.

Görgens (2002) found that the average ratio of the 50-year return period flood peaks estimated by the SDF methodology to the 50-year return period flood peaks estimated using the LP3 distribution and the observed data to be approximately $210 \%$. Hence, Görgens (2002) recommended that the SDF method should be seen as a conservative approach, similar to that of the RMF method, and the use of the SDF may result in significant over-design of some hydraulic structures which may make them to be uneconomical (e.g. dam spillways).

The SDF method was assessed at 5 additional stations not used in the development of the method in each of the 29 catchments and significant differences at some stations were noted between the design peak discharges computed using the at-site data and by the SDF method, although no distinct trends were evident (SANRAL, 2007). Van Bladeren (2005) noted some errors in the data used in the development of the SDF methodology and found that the method performed inconsistently; hence, region-specific adjustment methods were developed. As a consequence, Van Bladeren (2005) recommended that the SDF methodology should be refined with:

- Improved regionalisation with more stations.

- Re-estimation of catchment characteristics.

- The development of upper and lower growth curves to assess the results from the SDF method.

- Other methods to estimate design floods must be used in conjunction with the SDF methodology to ensure the results from the SDF method are reasonable.

A further assessment of the SDF was performed by Gericke (2010) who compared runoff coefficients from the existing regional SDF methodology with runoff coefficients computed from the observed flow data at quaternary catchment level and with adjusted runoff coefficients proposed by Van Bladeren (2005) in the C5 quaternary catchment (5 sites) and other selected catchments in South Africa (6 sites). The comparisons showed that the calibrated runoff coefficients at quaternary catchment level were generally less than those proposed by the SDF method, with differences exceeding a factor of three at some sites with little improvement using the adjusted runoff coefficients suggested by Van Bladeren (2005).

According to Smithers and Schulze (2003), the SDF method has the ingredients to overcome some of the deficiencies evident in the techniques currently used for design flood estimation in South Africa, but the use of a single rainfall site and outdated design rainfall values as developed by Adamson (1981), the subjective adjustments made, the method of incorporation of variability within regions, and the method of regionalisation, are all aspects that warrant further investigation and refinement.

Pegram (2003) developed a preliminary Modified Rational Formula (MRF) for South Africa by replacing the rainfall intensity term with a function that incorporates the median annual maximum rainfall, a scaling function of an extreme 
value distribution that includes the effect of return period, and rainfall duration. Pegram and Parak (2004) describe the MRF as a 'check formula' for estimating flood peaks on a wide range of catchment areas for any recurrence interval, and found that it was able to predict flood peaks of similar order to those observed.

Parak and Pegram (2006) calibrated the Rational Method runoff coefficient using design rainfall values estimated by the Regional L-Moment Algorithm and Scale Invariance (RLMA\&SI) method developed by Smithers and Schulze (2003) and peak discharge values from 29 catchments estimated using the run hydrograph method (Hiemstra and Francis, 1979). They found that the calibrated runoff coefficients did not, as expected, consistently increase with return period in all catchments which was attributed to the source of the estimated flood peaks used in the analysis. The calibrated runoff coefficients were found to be related to land use, slope, time of concentration and return period, but it was not possible to regionalise the calibrated coefficients. In addition, it was noted that the calibrated runoff coefficients were generally lower than the runoff coefficients published in the literature. Parak and Pegram (2006) concluded that the calibrated Rational Method can be used for both small and large catchments, but recommended that it should be used in conjunction with other methods.

The probabilistic Rational Method has been developed for use in Australia with the runoff coefficient for different return periods either mapped or related by regression to catchmentbased physical variables. Studies in Australia have shown the superior performance of the probabilistic Rational Method, which is suitable for catchments of up to $250 \mathrm{~km}^{2}$, compared to the very poor performance of the deterministic approach (Pilgrim and Cordery, 1993). Contrary to the deterministic approach, the probabilistic runoff coefficients did not show much variation with catchment characteristics (Pilgrim and Cordery, 1993).

\section{SCS-SA}

The SCS method for design flood estimation is widely used and has, in the USA, replaced the Rational Method (Pilgrim and Cordery, 1993), while Boughton and Droop (2003) believe it is the most widely used rainfall-runoff model in the world. This is attributed by Pilgrim and Cordery (1993) to the longer apparent database and the manner in which the physical catchment characteristics are incorporated. Inconsistencies in the application of the method are the result of the choice of procedures for estimating the time of concentration and in choosing a relevant Curve Number (CN). Pilgrim and Cordery (1993) summarise the following with regard to the SCS method:

- The SCS model performed poorly in simulating actual peak discharges from runoff plots in the USA.

- The assumed antecedent moisture conditions had a major effect on the results.

- The model performed better on catchments with sparse vegetation than on catchments with dense vegetation.

- The SCS method was applied in a probabilistic manner in Australia and the derived $\mathrm{CN}$ showed little agreement with those estimated by conventional means. The derived $\mathrm{CN}$ was affected both by the method used to estimate the catchment lag time and on the return period.

The above results led Pilgrim and Cordery (1993) to doubt the accuracy and validity of the SCS method and suggest that the results from the SCS method should be checked against observed flood data in the region in which it is applied. Cordery and Pilgrim (2000) express the opinion that the SCS method is vaguely intuitive and cannot be expected to provide reliable design estimates.

Haan and Schulze (1987) treated the input variables in the SCS equation as random variables in order to correctly transform the rainfall with a given exceedance probability into runoff with the same probability. They found that the traditional SCS method of accounting for antecedent moisture conditions resulted in reasonable estimates of runoff.

The SCS method as adapted for South Africa by Schmidt and Schulze (1987) utilised the developments and verifications by Schulze and Arnold (1979), Schulze (1982), Schmidt and Schulze (1984) and Dunsmore et al. (1986). These adaptations were computerised by Schulze et al. (1992) and the method is now widely used for the estimation of design floods from small catchments in South Africa. Alexander (2001) recommends the SCS method for agricultural catchments with areas $<8 \mathrm{~km}^{2}$.

The SCS method is not as sensitive as the Rational Method to user inputs. It can compute the entire hydrograph and is recommended for both urban and rural catchments with areas $<10$ $\mathrm{km}^{2}$ (Campbell et al., 1986; SANRAL, 1986). A further statistical analysis of the results presented by Campbell et al. (1986) was performed by Schulze et al. (1986), who excluded rainfall events less than $20 \mathrm{~mm}$, and concluded that the SCS-based models, particularly the South African adaptations, performed well enough to be recommended for design on a considerable range of land use and catchment size categories. An advantage of the SCS method is that full hydrographs are generated and not only peak discharges (SANRAL, 2007)

The adaptations for Southern African conditions to the SCS approach, as detailed by Schmidt and Schulze (1987), account for regional differences in median antecedent soil moisture conditions prior to large events and for the joint association between rainfall and runoff. Schmidt and Schulze (1987) utilised 712 relatively homogenous rainfall zones in South Africa and simulated daily hydrological responses for 3 soil depths, 3 soil textures and 3 land covers for a 30-day period prior to the 5 largest rainfall events in each year of rainfall record used. From these results, the median change in soil moisture was used to account for typical regional differences in soil moisture prior to large events, which is utilised to adjust the input Curve Number. In addition, the joint association method developed computes design flood discharges directly from the simulated runoff.

As detailed by Smithers and Schulze (2003), currently available improved computing power and available rainfall, land cover and soils databases could be utilised to further refine the method. For example, the regionalisation of South Africa could be improved, at the broadest scale, to reflect the 1946 quaternary catchments or 5838 quinary catchments into which South Africa has been delineated and, where necessary, could also reflect heterogeneity of soils and current or future land use within each quaternary or quinary catchment. The method used to account for regional differences in antecedent moisture conditions (AMC) could be improved by utilising improved modelling inputs. For example, estimates of reference potential evaporation as well as maximum evaporation (i.e. transpiration by vegetation and soil evaporation) could be improved by using currently available information and techniques. The use of median conditions to account for AMC needs to be re-evaluated and improved by the use of continuous simulation modelling. It is probable that the soil moisture status could 
be a function of the exceedance probability of the intended design. The method used to account for the joint association between rainfall and runoff could also be improved by the use of a continuous simulation approach. This could include events larger than those equivalent to the 20 -year return period, which is a limitation in the adaptation of the SCS technique for South Africa undertaken by Schmidt and Schulze (1987).

\section{New approaches}

In order to overcome some of the major limitations of event models, continuous simulation and joint probability approaches have been proposed (Rahman et al., 2002). Continuous simulation generates flow series for an extended period while joint probability focuses on the simulation of a large number of flood events while considering probability distributed inputs and model parameters, and their correlations, in order to derive the distribution of the floods (Rahman et al., 2002).

\section{Continuous simulation modelling}

Continuous simulation models attempt to represent the major processes which convert rainfall into runoff and hence the flood frequency distribution can be derived from the simulated results (Goel et al., 2000). Historical rainfall data or stochastic rainfall series are used to generate outflow hydrographs over long time periods and the simulated flow can be subjected to standard frequency analysis techniques. Thus, model parameters determined using a relatively short period of calibration and verification can be used together with a long climate series to yield flood frequency estimates (Calver and Lamb, 1995). If the model parameters can be related to the catchment characteristics, then the model parameters can be transferred to similar catchments.

Schulze (1989) argues for a continuous simulation modelling approach to design flood estimation, because:

- Long periods of record are necessary for accurate estimation of design values.

- Long series of observed flood data are generally not available, often contain inconsistencies and are frequently both non-homogeneous and non-stationary.

- In comparison to runoff data, longer data sets of rainfall of better quality are usually available for most regions in South Africa.

- The exceedance probability of floods is generally not related to the exceedance probability of rainfall, as assumed in simple event-based models.

The advantages of the simulation modelling approach include the following (ASCE, 1997; Boughton and Hill, 1997; Rahman et al., 1998; Reed, 1999):

- A complete hydrograph is generated and not only a peak discharge.

- No synthetic storms are required, as actual storm records are used and hence critical storm duration is not an issue.

- The use of a calibrated rainfall-runoff model avoids the needs for assumptions about losses.

- Antecedent moisture conditions (AMC) are modelled explicitly and hence any subjectivity in attempting to account for AMC is removed.

- The statistical analysis of output implies that the return period of the output is not assumed to be equal to that of the input rainfall.
The disadvantages of the simulation modelling approach include the following (ASCE, 1997; Rahman et al., 1998; Reed, 1999):

- The difficulties in adequately modelling the soil moisture balance and obtaining input data at the required temporal and spatial scale and the number of variables to calibrate may be substantial.

- The loss of 'sharp' events if the modelling time scale is too coarse.

- The extensive data requirements which result in significant time and effort to obtain and prepare the input data.

- The expertise required to determine parameter values such that historical hydrographs are adequately simulated.

Smithers et al. (2007) investigated the use of a continuous simulation modelling approach to estimate design floods in the Thukela Catchment in South Africa, where the frequency of simulated volumes and peak discharge are assessed directly, thus not making the assumption that the return period of the flood is equal to the return period of the input design rainfall. Smithers et al. (2007) found that the distribution of simulated volumes generally compared well with the distribution of the volumes of the observed data over the range of catchment areas considered in their study (approximately 100 to $2000 \mathrm{~km}^{2}$ ). The distribution of the simulated peak discharges generally compared well with the observed distribution for the smaller catchments $\left(<150 \mathrm{~km}^{2}\right)$, but were generally not as good for larger catchments. They recommended that the translation of the runoff volume into a hydrograph and associated peak discharge requires further refinement. This may involve investigating the estimation of catchment lag and further investigation into the performance of flood routing algorithms for application in ungauged catchments. As pointed out above, consistent and accurate estimation of catchment response times are necessary for design rainfall estimation.

Internationally, the success of a continuous simulation approach to design flood estimation is evident from many studies reviewed (e.g. Schulze, 1989; Calver and Lamb, 1995; Boughton and Hill, 1997; Rahman et al., 1998; Steel, 1998; Cameron et al., 1999; Houghton-Carr, 1999; Reed, 1999; Viviroli et al., 2009) and has been shown to be able to estimate the uncertainty bounds for flood frequency curves (Jones and Kay, 2007). The advantages of continuous simulation models include the simulation of the complete hydrograph and continuous simulation of antecedent moisture conditions. These need to be weighed against the challenges of input data preparation, assigning values to model parameters and regionalisation (Houghton-Carr, 1999). The currently available increased computing power and sub-daily rainfall and flow data in digital form, enables the continuous simulation of hydrographs to become a standard technique for estimating design floods (Cameron et al., 1999).

\section{Joint probabilities}

In the design event approach it is generally assumed that a unique combination of factors results in a flood with the same exceedance probability as that of the input rainfall. The joint probability approach recognises that a design flood could be the result of various combinations of flood-producing factors (Rahman et al., 1998). Probability-distributed inputs are used to form probability-distributed outputs. Hence, subjectivity in the selection of input and parameter values is eliminated by considering the inputs as random variables. 
The joint probability approach thus combines a deterministic rainfall-runoff model with stochastic inputs as the probability distribution and a correlation structure of the inputs (Rahman et al., 1998). Flood frequency distributions in 3 catchments in Victoria, Australia, were well produced by a joint probability approach (Rahman et al., 2002).

The joint probability approach may use the same models as the design event approach, but treats inputs and data as random variables. This results in output as a probability distribution instead of a single value. According to Pilgrim (1987) the joint probability approach is superior to the design event approach.

\section{Need for consistency}

An important aspect of design flood estimation is the need for consistency when each of the various methods are applied by different users, i.e., similar results should be obtained by different users when applying the same method. Alexander (1990) states that the subjectivity in the estimation of design storms is a major limitation in the consistent estimation of design floods in South Africa. For a specified catchment response time, the RLMA\&SI procedures developed by Smithers and Schulze (2003) to estimate design rainfall will, when applied on a 1' $\mathrm{x}$ 1' gridded scale in South Africa, overcome the subjectivity in design rainfall input. However, considerable inconsistency remains in the estimation of the catchment response time, and hence in the estimation of the critical duration of design rainfall and in the selection of other model inputs based on textbook values for the Rational Method and, to a lesser extent, for the SCS techniques.

\section{Impacts of climate change on design floods}

There is evidence that many natural systems are being affected by regional climate changes, particularly temperature (IPCC, 2007). According to IPCC (2007) and Bates et al. (2008), it is 'very likely' that the frequency of heavy precipitation events, and proportion of total rainfall from heavy falls, has increased over most areas and extreme events will be become more frequent, although the mean rainfall may decrease in some regions. At the global scale, this will result in some areas experiencing increased runoff, while other areas will have less runoff and trends in runoff do not necessarily follow the trend in precipitation (Bates et al., 2008). The changes in the characteristics and distribution of the rainfall and runoff will impact the estimation of design floods. For example, the impact of climate change on design rainfall needs to be quantified to assess the impact on the estimated design flood. The impact on the method of analysis also needs to be investigated as, for example, the observed data series may not be stationary, as frequently assumed when performing flood frequency analysis. For non-stationary data, the statistical characteristics of the non-stationarity need to be modelled and projected into the design life of the structure (Strupczewski et al., 2001). According to results generated by Knoesen (2011), both design rainfall and design floods are expected to increase in South Africa as a consequence of climate change, with the increase in design floods being larger than those for design rainfall.

\section{Summary of recommendations}

From the above review of the literature, it is clear that new and updated methods of design flood estimation are required in order to keep up to date with international practices and to improve the estimates based on longer periods of records and improved information currently available. Smithers and Schulze (2003) summarised the following research needs in design flood hydrology for South Africa, taking into account the need to introduce new and internationally accepted techniques and to refine existing techniques:

- A continuous simulation approach to design flood estimation should be further evaluated and developed. Such an approach overcomes many of the limitations of the design event models and can accommodate current and projected future conditions in a catchment, such as anticipated land use or climate change. Limitations of the gauged flow data and changes in catchment conditions within the period of gauging may be overcome using this approach. It may be necessary to combine this approach with, for example, unit hydrographs to estimate the peak discharge. The output from a continuous simulation approach could be pre-run and packaged for hydrologically homogeneous regions/ quaternary catchments to enable simple and rapid use by practitioners. An initial study on the use of continuous simulation for design flood estimation in South Africa has been conducted by Smithers et al. (2007) with mixed results, as summarised above.

- Areal Reduction Factors (ARFs), which convert design rainfall estimated at a point to an areal rainfall, need to be re-investigated in the light of recent extreme events, utilising the longer periods of record now available for analysis. In addition, the way in which ARFs may vary in South Africa with recurrence interval and with rainfall-producing mechanisms also needs to be investigated.

- Revision and refinement of techniques for the temporal disaggregation of daily rainfall into shorter durations and spatial estimation of daily rainfall using, for example, remotely-sensed rainfall using radar and satellite techniques. Some initial investigations into improved estimation of historical catchment rainfall have been conducted by Frezghi and Smithers (2008) and into temporal disaggregation of daily rainfall by Knoesen and Smithers (2008).

- A joint probability approach to design flood estimation, which derives the flood frequency distribution by the incorporation of uncertainties in the inputs to the model, should be investigated.

- A revision and updating of the SCS-SA method for design flood estimation on small catchments in South Africa should be undertaken to incorporate both the increased spatial resolution of soils and land cover/use information now available and the updated and improved design rainfall values, while simultaneously improving the technique to account for antecedent moisture conditions.

- A regional statistical approach for flood frequency estimation should be developed, i.e. the identification of homogeneous regions, the development of growth curves for each reach region and the development of algorithms to estimate the scaling factor at ungauged sites. Regionalisation based both on a cluster analysis of site characteristics and the region of influence approach, as adopted by the Flood Estimation Handbook (FEH) for the UK (Reed, 1999), should be investigated. The pooled approach developed by Görgens (2007) utilises existing regions in the development of an index flood method for South Africa.

- Improved and consistent methods to estimate catchment lag should be evaluated as catchment response time has a direct 
impact on both the design rainfall intensity input and the simulated peak discharge.

- A probabilistic approach to the use of the Rational Method should be investigated. The observed streamflow data required for this approach could be supplemented with the output of the continuous simulation approach, i.e., this could constitute one of the simple approaches which could be synthesised from the output of the continuous simulation approach. Alexander (2002a; 2002b; 2002d) has developed a 'standard design flood' using this approach, which may require further refinement. In addition, a modified, probabilistic Rational Method has been proposed (Pegram, 2003; Parak and Pegram, 2006; Pegram and Parak, 2004).

- The run-hydrograph technique should be re-evaluated and, if necessary, further refined for use by practitioners. A joint peak-volume methodology and an index flood method to estimate design floods in South Africa has been developed (Görgens, 2007), but may be difficult to apply in its current form by practitioners.

- The unit hydrograph approach including the estimation of storm losses should be refined, utilising longer records, improved regionalisation and currently available detailed databases and geographic information systems.

In addition, Cullis et al. (2007) made recommendations for further research needs to extreme flood estimation in South Africa which included the following:

- Modernisation of probable maximum precipitation envelopes for South Africa and spatial distribution of extreme rainfall events.

- Investigation into the use of exceedance probabilities associated with the extreme floods (e.g. RMF and PMF), as used internationally.

- The selection and consistent use of an appropriate probability distribution for design flood estimation.

- Updating and refinement of the Kovacs RMF K-regions (Kovacs, 1988).

- Development of refined methodologies for regionalisation and pooling practices for design flood estimation.

- Development of consistent approaches for the standardisation of data and estimation of catchment response characteristics (e.g. index flood).

Gericke (2010) recommended, inter alia, the following refinements to the SDF methodology:

- Refinement of the SDF boundaries to single or multiple quaternary catchments.

- Calibration of runoff coefficients using an updated database of flow data from both gauging weirs and dam records

- Development of catchment-based regression relationship.s to estimate the runoff coefficients to apply the method in ungauged catchments.

- Improvement in the estimation of design rainfall for catchments based on the RLMA\&SI methodology developed by Smithers and Schulze (2003).

In addition, Gericke (2010) included the following recommendations for improving design flood estimation in South Africa:

- The compilation of all available hydrological data and the estimation of design events using the updated databases.

- The use of a consistent probability distribution to estimate design floods.

- The development of updated rainfall areal reduction factors for South Africa.

\section{Discussion and conclusions}

From the above review of the literature and recommendations for research, it is clear that new and updated methods of design flood estimation are required in order to keep up todate with international practices, to improve the estimates based on longer periods of records and improved information currently available, and to account for the impacts of climate change on design flood estimation.

Design flood estimation may be performed by a frequency analysis of observed flows where these are available and are adequate in length and quality. While the analysis may be performed at a single site, a regional approach should preferably be adopted. The advantages of a regional approach to frequency analysis for design flood estimation are evident from the studies reviewed. This has led to the adoption of a regional approach as the recommended approach for design flood estimation by some countries (e.g. Australia and UK). The indexflood approach developed by Görgens (2007) for application in South Africa should be further developed for use in practice and refined regionalisation should be investigated.

For direct statistical analysis, Alexander $(1990 ; 2001)$ recommends either the Method of Moments or Probability Weighted Moments for fitting distributions. The literature indicates that L-moments are widely used and have been adopted as a standard approach in, for example, the UK. Although some caution and criticism of the use of L-moments is also evident in the literature, further investigation of L-moments for possible general use in South Africa is warranted. The development of a methodology to account for non-stationary data when performing a frequency analysis needs to be developed.

When no recorded streamflow data are available at the site of interest, or the records are inadequate, the recommended rainfall-runoff event-based methods for design flood estimation in South Africa include the unit hydrograph, Rational Method and SCS methods.

No developments or refinements of the unit hydrograph methods have been published since they were developed by the HRU (1972) in the late 1960s and early 1970s. Subsequent to these studies, regional techniques for frequency analysis have become the standard and preferred approach in some countries. In addition, longer rainfall and streamflow records are currently available for analysis, computing power has expanded enormously and detailed databases of climatic and catchment physiographic characteristics are available at a national scale. While the regionalisation of South Africa into 9 veld zone types, based on data from only 92 flow gauging stations, was pioneering work at the time, it is postulated that refined regionalisation of homogeneous hydrological response regions in the country is now possible.

The event-based methods used in South Africa are generally applied in a deterministic manner and hence suffer from the limitations of this approach, which includes the uncertainty of the real exceedance probability associated with the computed design flood, the spatial and temporal distribution of rainfall and conditions in the catchment prior to extreme events. Although a return period adjustment factor for the application of the Rational Method in South Africa is advocated, the method is still applied in a deterministic manner and the adjustment factor does not constitute a probabilistic approach. A probabilistic approach would enable the conversion of a design rainfall event into a design flood event with the same return period.

The calibrated Rational method developed by Alexander (2002a; 2002b; 2002d), and termed the 'Standard Flood', 
is a probabilistic-based approach which has the ingredients to overcome some of the deficiencies evident in the techniques currently used for design flood estimation in South Africa. However, independent studies have shown that the method results in very conservative design floods. In addition, the use of single site and outdated design rainfall values, the subjective adjustments made, the method of incorporation of variability within regions and the method of regionalisation are all aspects which warrant further investigation.

The adaptions for Southern African conditions to the SCS approach, as detailed by Schmidt and Schulze (1987), account for regional differences in median antecedent soil moisture conditions prior to large events and for the joint association between rainfall and runoff. However, improved computing power and currently available databases could be utilised to further refine the method. For example, the regionalisation of South Africa could be improved to, at the broadest scale, reflect the 1946 quaternary catchments into which South Africa has been delineated and, where necessary, could also reflect heterogeneity of soils and current land use within each quaternary catchment. The method used to account for regional differences in AMC could be improved by utilising improved modelling inputs. The use of median conditions to account for AMC needs to be reevaluated and possibly improved by the use of continuous simulation modelling. It is probable that the soil moisture status could be a function of the exceedance probability of the intended design. The method used to account for the joint association between rainfall and runoff could also be improved by the use of a continuous simulation approach and could include events larger than those equivalent to the 20 -year return period, which is a limitation of the current version of the SCS-SA model.

An important aspect is the need for consistency when the various methods of design flood estimation methods are applied by different users, i.e., similar results should be obtained by different users when applying the same method. Consistent design rainfalls can be estimated for South Africa. However, considerable inconsistency remains in the estimation of the catchment response time which has a direct impact on the estimation of design floods.

In a review of the current state of the art of flood frequency analysis, the gap between flood research and practice is emphasised by Cordery and Pilgrim (2000), with research being required to improve the estimates of both specific and probabilistic floods. Although the gap between flood research and practice may not be large in South Africa, with relatively little research having been undertaken in the past 30 years, the need to refine existing methods and to evaluate new methods which have been adopted for design flood estimation in other countries, currently requires urgent attention and funding in South Africa.

\section{References}

ADAMSON PT (1981) Southern African Storm Rainfall. Technical Report No. TR 102. Department of Water Affairs, Pretoria, South Africa.

ALEXANDER WJR (1990) Flood Hydrology for Southern Africa. SANCOLD, Pretoria, South Africa.

ALEXANDER WJR (2001) Flood Risk Reduction Measures. University of Pretoria, Pretoria, South Africa.

ALEXANDER WJR (2002a) The Standard Design Flood. J. S. Afr. Inst. Civ. Eng. 44 (1) 26-31.
ALEXANDER WJR (2002b) The Standard Flood - Theory and Practice. URL: http://www.up.ac.za/academic/civil/divisions/ water/upflood.html (Accessed 1 April 2002).

ALEXANDER WJR (2002c) Statistical Analysis of Extreme Floods. URL: http://www.up.ac.za/academic/civil/divisions/water/upflood. html (Accessed 1 April 2002).

ALEXANDER WJR (2002d) Use Manual: The Standard Flood - a New Design Philosophy. URL: http://www.up.ac.za/academic/civil/ divisions/water/upflood.html (Accessed 1 April 2002).

ASCE (1997) Flood-Runoff Analysis. ASCE Press, New York. 176 pp.

AUSTRALIAN INSTITUTION OF ENGINEERS (1977) Australian Rainfall and Runoff: Guide to Flood Estimation. EA Books, Crows Nest, Australia. 374 pp.

BATES B, KUNDZEWICZ ZW, WU S and PALUTIKOF J (2008) Climate Change and Water. IPCC Secretariat, Geneva, Switzerland. $210 \mathrm{pp}$.

BAUER SW and MIDGLEY DC (1974) A Simple Procedure for Synthesizing Direct Runoff Hydrographs. Hydrological Research Unit, University of the Witwatersrand, Johannesburg. $55 \mathrm{pp}$.

BEVEN KJ (2000) Rainfall-Runoff Modelling: The Primer. John Wiley and Sons, Chichester. $360 \mathrm{pp}$.

BOBEE B and RASMUSSEN PF (1995) Recent Advances in Flood Frequency Analysis. U.S. National Report 1991-1994. Twenty-First General Assembly International Union of Geodesy and Geophysics Boulder, Colorado - July 2-14, 1995. 1111-1116.

BOUGHTON W and DROOP O (2003) Continuous simulation for design flood estimation - A review. Environ. Model. Softw. 18 309-318.

BOUGHTON W and HILL P (1997) A Design Flood Estimation Procedure Using Data Generation and a Daily Water Balance Model. Report 97/8, Cooperative Research Centre for Catchment Hydrology, Monash University, Clayton, Victoria, Australia. 39 pp.

BURN DH (1990) An appraisal of the "Region of Influence" approach to flood frequency analysis. Hydrol. Sci. J. 35 (2) 149-165.

BURN DH (1990) Evaluation of regional flood frequency analysis with a region of influence approach. Water Resour. Res. 26 (10) 2257-2265.

CALVER A and LAMB R (1995) Flood frequency estimation using continuous rainfall-runoff modelling. Phys. Chem. Earth 20 (5-6) 479-483.

CAMERON DS, BEVEN KJ, TAWN J, BLAZKOVA S and NADEN P (1999) Flood frequency estimation by continuous simulation for a gauged upland catchment (with uncertainty). J. Hydrol. 219 169-187.

CAMPBELL GV, WARD AD and MIDDLETON BJ (1986) An Evaluation of Hydrological Techniques for Estimating Floods from Small Ungauged Catchment. WRC Report No. 139/2/87. Water Research Commission, Pretoria, South Africa. 78 pp.

CHOW VT, MAIDMENT DR and MAYS LR (1988) Applied Hydrology. McGraw-Hill, New York, USA.

CORDERY I and PILGRIM DH (2000) The State of the Art of Flood Prediction. In: Parker DJ (ed.) Floods. Volume II. Routledge, London. 185-197.

CULLIS J, GÖRGENS AHM and LYONS S (2007) Review of the Selection of Acceptable Flood Capacity for Dams in South Africa in the Context of Dam Safety. WRC Report No. 1420/1/07. Water Research Commission, Pretoria, South Africa.

CUNNANE C (1989) Statistical Distributions for Flood Frequency Analysis. WMO Report No. 718, World Meteorological Organization, Geneva, Switzerland.

DUNSMORE SJ, SCHMIDT EJ and SCHULZE RE (1986) Antecedent Soil Moisture in Design Runoff Volume Estimation. WRC Report No. 155/1/86. Water Research Commission, Pretoria, South Africa. $110 \mathrm{pp}$.

FREZGHI MS and SMITHERS JC (2008) Merged rainfall fields for continuous simulation modelling. Water SA 34 (5) 523-528.

GABRIELE S and ARNELL N (1991) A hierarchical approach to regional flood frequency analysis. Water Resour. Res. 27 (6) 1281-1289.

GERICKE OJ (2010) Evaluation of the SDF Method Using a Customised Design Flood Estimation Tool. Thesis, University of Stellenbosch Stellenbosch, South Africa. 480 pp. 
GINGRAS D and ADAMOWSKI K (1994) Performance of L-moments and nonparametric flood frequency analysis. Can. J. Civ. Eng. 21 (5) $856-862$.

GOEL NK, KUROTHE RS, MATHUR BS and VOGEL RM (2000) A derived flood frequency distribution for correlated rainfall intensity and duration. J. Hydrol. 228 (1/2) 56-67.

GÖRGENS AHM (2002) Design Flood Hydrology. In: Basson G (ed.) Design and Rehabilitation of Dams. Institute for Water and Environmental Engineering, Department of Civil Engineering, University of Stellenbosch, South Africa. 460-524.

GÖRGENS AHM (2007) Joint Peak-Volume (JPV) Design Flood Hydrographs for South Africa. WRC Report No. 1420/3/07. Water Research Commission, Pretoria, South Africa.

GÖRGENS AHM, LYONS S, HAYES L, MAKHABANE M and MALULEKE D (2007) Modernised South African Design Flood Proactice in the Context of Dam Safety. WRC Report No. 1420/2/07. Water Research Commission, Pretoria, South Africa

GUTTMAN NB (1992) Regional Precipitation Quantile Values for the Continental U.S. Computed from L-Moments. RC 18258, IBM Research Division, T.J. Watson Research Division, New York, USA.

GUTTMAN NB (1993) The Use of L-Moments in the Determination of Regional Precipitation Climates. National Climate Centre, Asheville, North Carolina, USA.

GUTTMAN NB, HOSKING JRM and WALLIS JR (1993) Regional precipitation quantile values for the continental US computed from L-moments. J. Clim. 6 (December) 2326-2340.

HAAN CT and SCHULZE RE (1987) Return period flow prediction with uncertain parameters. Trans. Am. Soc. Agric. Eng. 30 (3) $665-669$.

HERBST PH (1968) Flood Estimation for Ungauged Catchments. Technical Report No. 46, Division of Hydrology, Pretoria, South Africa.

HIEMSTRA LA (1981) Run hydrographs for prediction of flood hydrographs. J. Hydraul. Div. ASCE (New York) 107 (2) 759-775.

HIEMSTRA LA and FRANCIS DM (1979) The Runhydrograph Theory and Application for Flood Predictions. Water Research Commission, Pretoria, South Africa. 63 pp.

HIEMSTRA LAV, ZUCCHINI WS and PEGRAM GGS (1976) A method of finding the family of runhydrographs for given return periods. J. Hydrol. 30 95-103.

HOSKING JRM (1995) The use of L-moments in the analysis of censored data. In: Balakrishnan N (ed.). Recent Advances in LifeTesting and Reliability. CRC Press, Boca Raton, Florida, USA. 545-564.

HOSKING JRM and WALLIS JR (1987) An index flood procedure for regional rainfall frequency analysis. EOS, Trans. Am. Geophys, Union 68312

HOSKING JRM and WALLIS JR (1993) Some statistics useful in a regional frequency analysis. Water Resour. Res. 29 (2) 271-281.

HOSKING JRM and WALLIS JR (1995) A comparison of unbiased and plotting-position estimators of L-moments. Water Resour. Res. 31 (8) 2019-2025

HOSKING JRM and WALLIS JR (1997) Regional Frequency Analysis: An Approach Based on L-Moments. Cambridge University Press, Cambridge. 224 pp.

HOUGHTON-CARR H (1999) Flood Estimation Handbook. Volume 4. Restatement of the Flood Studies Report Rainfall-Runoff Method. Institute of Hydrology, Wallingford, Oxfordshire, UK, $288 \mathrm{pp}$.

HRU (1972) Design Flood Determination in South Africa. Report No. 1/72, Hydrological Research Unit, Department of Civil Engineering, University of the Witwatersrand, Johannesburg.

IACWD (1982) Guidelines for Determining Flood Flow Frequency. Inter-agency Advisory Committee on Water Data, Department of Interior, USGS, Reston, Vancouver, USA

IPCC (2007) Climate Change 2007: Synthesis Report. Intergovernmental Panel on Climate Change. $52 \mathrm{pp}$.

JONES DA and KAY AL (2007) Uncertainty analysis for estimating flood frequencies for ungauged catchments using rainfall-runoff models. Adv. Water Resour. 30 1190-1204.

KACHROO RK, MKHANDI SH and PARIDA BP (2000) Flood frequency analysis of Southern Africa: I. Delineation of homogeneous regions. Hydrol. Sci. J. 45 (3) 437-447.

KARIM A and CHOWDHURY JU (1995) A comparison of four distributions used in flood frequency analysis in Bangladesh. Hydrol. Sci. J. 40 (1) 55-66.

KJELDSEN TR, SMITHERS JC and SCHULZE RE (2001) Flood frequency analysis at ungauged sites in the KwaZulu-Natal Province, South Africa. Water SA 27 (3) 315-324.

KJELDSEN TR, SMITHERS JC and SCHULZE RE (2002) Regional flood frequency analysis in the KwaZulu-Natal Province, South Africa, using the index-flood method. J. Hydrol. 255 (1-4) 194-211.

KNOESEN DM (2011) Integrating Hydro-Climatic Hazards and Climate Change as a Tool for Adaptive Water Resources Management in the Orange River Catchment. Unpublished Ph.D. thesis, School of Bioresources Engineering and Environmental Hydrology, University of KwaZulu-Natal, Pietermaritzburg, South Africa. 255 pp.

KNOESEN DM and SMITHERS JC (2008) The development and assessment of a regionalised daily rainfall disaggregation model for South Africa. Water SA 34 (3) 323-330.

KOVACS ZP (1988) Regional Maximum Flood Peaks in South Africa. Technical Report TR137, Department of Water Affairs, Pretoria, South Africa.

LETTENMAIER DP (1985) Regionalisation in flood frequency analysis - is it the answer?, US-China Bilateral Symposium on the Analysis of Extraordinary Flood Events, October 1985, Nanjing, China.

LIN B and VOGEL JL (1993) A Comparison of L-Moments with Method of Moments. In: Kuo CY (ed.) Engineering Hydrology. ASCE, New York. 443-448.

MAIDMENT DR (1993) Handbook of Hydrology. McGraw-Hill, New York, USA.

McPHERSON D (1984) Comparison of annual flood peaks calculated by various methods. In: Maaren H (ed.) South African National Hydrology Symposium. Technical Report TR119, Department of Environmental Affairs, Pretoria, South Africa. 236-250.

MKHANDI SH, KACHROO RK and GUNASEKARA TAG (2000) Flood frequency analysis of Southern Africa: II. Identification of regional distributions. Hydrol. Sci. J. 45 (3) 449-464.

NANDAKUMAR N, WEINMANN PE, MEIN RG and NATHAN RJ (1995) Estimation of Extreme Rainfalls for Victoria Using the CRC-Forge Method. Report 974, Cooperative Research Centre for Catchment Hydrology, Monash University, Clayton, Victoria, Australia. 117 pp.

NORTJE J (2010) Estimation of extreme flood peaks by selective statistical analyses of relevant flood peak data within similar hydrological regions. J. S. Afr. Inst. Civ. Eng. 52 (2) 48-57.

NTC (1981) Handleiding Vir Paddreinering. National Transport Commission, Directorate of Land Transport, Pretoria, South Africa. $135 \mathrm{pp}$.

PARAK M and PEGRAM GGS (2006) The rational formula from the runhydrograph. Water $S A 32$ (2) 163-180.

PEGRAM GGS (1994) Hydrologic Estimates (Chapter 2). Committee of State Road Authorities, Pretoria, South Africa. 25 pp.

PEGRAM GGS (2003) Rainfall, rational formula and regional maximum flood - Some scaling links. Aust. J. Water Resour. 7 (1) 29-39.

PEGRAM GGS and PARAK M (2004) A review of the regional maximum flood and rational formula using geomorphological information and observed floods. Water SA. 30 (3) 377-392.

PILGRIM DH (1987) Australian Rainfall and Runoff: A Guide to Flood Estimation. 3rd Revised Edition, Volume 1. Institution of Engineers, Barton, ACT, Australia. 385 pp.

PILGRIM DH and CORDERY I (1993) Chapter 9: Flood Runoff. In: Maidment DR (ed.) Handbook of Hydrology. McGraw-Hill, New York, USA.

PILON PJ and ADAMOWSKI K (1992) The value of regional information to flood frequency analysis using the method of L-moments. Can. J. Civ. Eng. 19 (1) 137-147.

PITMAN WV and MIDGLEY DC (1967) Flood studies in South Africa: Frequency analysis of peak discharges. Trans. S. Afr. Inst. Civ. Eng. August 1967. 
POTTER KW (1987) Research on flood frequency analysis: 19831986. Rev. Geophys. 25 (2) 113-118.

POTTER KW and LETTENMAIER DP (1990) A Comparison of regional flood frequency estimation methods using a resampling method. Water Resour. Res. 26 (3) 415-424.

RAHMAN A, HOANG TMT, WEINMANN PE and LAURENSON EM (1998) Joint Probability Approaches to Design Flood Estimation: A Review. Report 98/8, Cooperative Research Centre for Catchment Hydrology, Monash University, Clayton, Victoria, Australia, $70 \mathrm{pp}$.

RAHMAN A, WEINMANN PE, HOANG TMT and LAURENSON EM (2002) Monte Carlo simulation of flood frequency curves from rainfall. J. Hydrol. 256 196-210.

REED D (1999) Flood Estimation Handbook. Volume 1: Overview. Institute of Hydrology, Wallingford, Oxfordshire, UK. 108 pp.

REIS DS and STEDINGER JR (2005) Bayesian MCMC flood frequency analysis with historical information. J. Hydrol. 313 97-116.

ROBERTS DF (1963) Annual Flood Peak Probabilities. Professional Paper 20, Department of Water Affairs, Pretoria, South Africa.

ROBERTS DF (1965) The Empirical Determination of Flood Peak Probabilities. Technical Report No. 33, Division of Hydrology, Department of Water Affairs, Pretoria, South Africa.

SANRAL (1986) Road Drainage Manual. South African National Roads Agency Ltd, Pretoria, South Africa.

SANRAL (2007) Drainage Manual ( $5^{\text {th }}$ edn.). South African National Roads Agency Ltd, Pretoria, South Africa. 420.

SCHAEFER MG (1990) Regional analyses of precipitation annual maxima in Washington State. Water Resour. Res. 26 (1) 119-131.

SCHMIDT EJ and SCHULZE RE (1984) Improved Estimates of Peak Flow Rates Using Modified SCS Lag Equations. WRC Report No. 63/1/84. Water Research Commission, Pretoria, South Africa. $145 \mathrm{pp}$

SCHMIDT EJ and SCHULZE RE (1987) Flood Volume and Peak Discharge from Small Catchments in Southern Africa Based on the SCS Technique. WRC Report No. TT 31/8. Water Research Commission, Pretoria, South Africa. 164 pp.

SCHULZE RE (1982) Adapting the SCS Stormflow Equation for Application to Specific Events by Soil Moisture Budgeting. ACRU Report No. 15, Department of Agricultural Engineering, University of Natal, Pietermaritzburg, South Africa. 63 pp.

SCHULZE RE (1989) Non-stationary catchment responses and other problems in determining flood series: A case for a simulation modelling approach. In: Kienzle SW and Maaren H (eds.) Proceedings of the Fourth South African National Hydrological Symposium. SANCIAHS, Pretoria, South Africa. 135-157.

SCHULZE RE and ARNOLD H (1979) Estimation of Volume and Rate of Runoff in Small Catchments in South Africa. ACRU Report No. 8, Department of Agricultural Engineering, University of Natal, Pietermaritzburg, South Africa. 79 pp.

SCHULZE RE, NEUWIRTH S and WESTON DR (1986) Statistical Assessment of Hydrological Simulations Presented in "an Evaluation of Hydrological Techniques for Making Flood Estimations on Small Ungauged Catchments". Report submitted to the Water Research Commission, Pretoria. Department of Agricultural Engineering, University of Natal, Pietermaritzburg, South Africa. 21 pp.

SCHULZE RE, SCHMIDT EJ and SMITHERS JC (1992) PC-Based SCS Design Flood Estimates for Small Catchments in Southern Africa. ACRU Report 40, Department of Agricultural Engineering, University of Natal, Pietermaritzburg, South Africa. 47 pp.

SMITHERS JC, CHETTY KT, FREZGHI MS, KNOESEN DM and TEWOLDE MH (2007) Development and Assessment of a Continuous Simulation Modelling System for Design Flood
Estimation. WRC Report No. 1318/1/07. Water Research Commission, Pretoria, South Africa. 210 pp.

SMITHERS JC and SCHULZE RE (2000) Development and Evaluation of Techniques for Estimating Short Duration Design Rainfall in South Africa. WRC Report No. 681/1/00, Water Research Commission, Pretoria, South Africa. 356 pp.

SMITHERS JC and SCHULZE RE (2000) Long Duration Design Rainfall Estimates for South Africa. WRC Report No. 811/1/00, Water Research Commission, Pretoria, South Africa. 69 pp.

SMITHERS JC and SCHULZE RE (2001) Design Runoff Estimation: A Review with Reference to Practices in South Africa. Proc. Tenth South African National Hydrology Symposium, 26-28 September, 2001, School of BEEH, University of Natal, Pietermaritzburg, South Africa.

SMITHERS JC and SCHULZE RE (2003) Design Rainfall and Flood Estimation in South Africa. WRC Report No. 1060/01/03. Water Research Commission, Pretoria, South Africa. 155 pp.

STEDINGER JR, VOGEL RM and FOUFOULA-GEORGIOU E (1993) Frequency Analysis of Extreme Events. McGraw-Hill, New York, USA.

STEEL ME (1998) Recent Scottish hydroclimatology: Evaluation of flood events using historical rainfall series. Proc. Second International Conference on Climate and Water, Helsinki University of Technology, Finland. 400-409.

STRUPCZEWSKI WG, SINGH VP and FELUCH W (2001) Nonstationary approach to at-site flood frequency modelling I. Maximum likelihood estimation. J. Hydrol. 248 123-142.

USWRC (1976) Guidelines for Determining Flood Flow Frequency. Bulletin \#17, United States Water Resources Council, Reston, VA, USA.

VAN BLADEREN D (1993) Application of historical flood data in flood frequency analysis, for the Natal and Transkei Region. In: Lorentz SA, SW Kienzle and MC Dent (eds.) Proceedings of the Sixth South African National Hydrological Symposium. Department of Agricultural Engineering, University of Natal, Pietermaritzburg, South Africa. 359-366.

VAN BLADEREN D (2005) Verification of the Proposed Standard Design Flood (SDF). Report No: 344512/1, SRK Consulting, Pretoria, South Africa. 49 pp.

VAN DER SPUY D and RADEMEYER PF (2010) Flood Frequency Estimation Methods as Applied in the Department of Water Affairs. Department of Water Affairs, Pretoria, South Africa. $98 \mathrm{pp}$.

VAN DIJK M (2005) Upflood - Flood Analysis Programs. Sinotech CC Pretoria, South Africa. URL: http://www.sinotechcc.co.za/ Software/UPFLOOD/upflood.html\#Package. (Accessed 1 July 2005).

VIVIROLI D, MITTELBACH H, GURTZ J and WEINGARTNER $R$ (2009) Continuous simulation for flood estimation in ungauged mesoscale catchments of Switzerland - Part II: Parameter regionalisation and flood estimation results. J. Hydrol. 377 208-225.

VOGEL RM and FENNESSY NM (1993) L-moments diagrams should replace product moment diagrams. Water Resour. Res. 29 (6) 1746-1752.

VOGEL RM, MCMAHON TA and CHIEW FHS (1993) Floodflow frequency model selection in Australia. J. Hydrol. 146 (1-4) 421-449.

VOGEL RM, THOMAS WO and MCMAHON TA (1993) Flood-flow frequency model selection in Southwestern United States. J. Water Resour. Plann. Manage. 119 (3) 353-366.

WALLIS JR (1993) Regional Frequency Studies Using L-Moments. Pergamon Press, Oxford, UK. 468-476.

ZRINJI Z and BURN DH (1994) Flood frequency analysis for ungauged sites using a region of influence approach. J. Hydrol. $1531-21$. 